\title{
Study of cultural competence in male and female managers of training hospitals in Isfahan
}

\author{
Ahmadreza Raeisi ${ }^{1}$, Mohanna Rajabi $^{2^{*}}$ \\ ${ }^{1}$ Health Management and Economics Research Center, School of Management and Medical Information, \\ Isfahan University of Medical Sciences, Isfahan, Iran. \\ ${ }^{2}$ School of Management and Medical Information, Isfahan University of Medical Sciences, Isfahan, Iran.)
}

\begin{abstract}
Intruduction: Effective communication and interaction between managers and staff is a prerequisite for organization success. Without effective interaction between managers and staff, hospitals can't achieve their mission which is public health promotion. Cultural competence is known as a strategy for effective communication and a key factor in management for any organization. The aim of this study was survey of cultural competence in male and female managers of training hospitals in Isfahan. : This Methods and Material: This study was a descriptive-analytic study in which we determined the male and female hospital managers' level of cultural competence in training hospitals at Isfahan in summer 2015. The study populations were hospital senior managers in training hospitals. Data were collected via self-made questionnaire that validity and reliability was confirmed. The questionnaire consist of 30 questions related to three dimension of cultural competence, including cultural awareness, cultural knowledge, and vultural skills. The statistical analysis was performed using Spss 16. For descriptive analysis we used mean and standard deviation and for inferential statistical analysis we used Independent T-test (P.value<.05).

Results: The findings indicate that managers have a high level of cultural competence and there was no significant difference between male and female managers' cultural competence in training hospitals.

Conclusions: Based on our study and other researches Cultural awareness, cultural knowledge and cultural skills are critical element for effective interaction and communication between people and should be used for evaluating and achieving high level of cultural competence
\end{abstract}

\section{Keywords - Competence, Cultural competence, hospital manager, training hospital}

\section{INTRODUCTION}

Hospitals are organizations that provide health care services in urban and rural area and play a fundamental role in public health promotion and fulfillment of national health system mission and goals [1-3]. Since most of the activities and processes in hospital are based on interpersonal communication and interaction, optimal provision of services and process improvement is possible only with participation of all hospital's staff $[1,4,5]$. Cultural, racial, and ethnical diversity in hospital staff Shape the communication and interaction between people from different cultural and socioeconomic background [6]. Staff are the most important resources in health care organizations, especially hospitals [7] and a key factor for achieving organizational performance [8]. Communication between managers and staff in hospital is inherently important and achieving hospital's mission is not possible without full participation of all staff [7, 9].Effective communication and interaction between managers and staff is a prerequisite for organization success, without effective interaction hospitals can't achieve their mission which is delivery of physical and psychological services [10-13]. Cultural competence is known as a strategy for effective communication and a key factor in management for any organization [14, 15]. Cultural competency between managers, staff, patient, and customer has been recognized as an important issue relevant to all health system and the final outcome of a culturally competent health system is the provision of efficient and effective services to the community is served [14, 16, 17]. Cross (1989) state that cultural competence is a set of congruent behaviors, attitudes, and policies that come together in a system, agency, or among professionals and enables that system, agency, or those professionals to work effectively in cross-cultural situation [18]. In Campinha-Bacote's model of cultural competence in health care delivery, cultural competence is viewed as the ongoing process in which the health care provider continuously strives to achieve the ability to effectively work within the cultural context of the client including individual, family, and the community [19]. She promote a five-component system for cultural competence in healthcare delivery, which focuses on cultural awareness, cultural knowledge, cultural skills, cultural encounters and cultural desire [19]. These are linked in that cultural desire is seen as an attribute that allow a person to genuinely seek cultural 
encounters, obtain cultural knowledge and skills, make culturally sensitive communication and assessments and accepted and adapted to the process of cultural awareness [19].Intercultural communication competence is commonly known as the knowledge, motivation, and skills to interact effectively and appropriately with members of different cultures [20]. Ineffective intercultural communication between manager and staff can lead to stress, causing anxiety, poor performance, conflict, and job dissatisfaction $[6,21]$. Therefore it is necessary that managers continuously develop their skill, knowledge and awareness in cultural and social issues to create an environment in which hospital staff are able to do their best to achieve the goals of the hospital [22].The present study aim was to investigate the level of cultural competence in male and female senior managers of training hospitals in Isfahan With emphasis on cultural awareness, cultural knowledge, and cultural skills.

\section{MATERIALS AND METHODS}

\subsection{Study design, variables and data collection}

This study was a descriptive-analytic study in which we determined the male and female hospital managers' level of cultural competence including cultural Awareness, Knowledge, and Skills. The study populations were all 44 senior managers of training hospitals located in Isfahan in summer 2014. Data were collected via self-made questionnaire. The questionnaire consisted of demographic characteristic of participants and 30 questions that divided into three section including cultural Awareness, cultural Knowledge, and cultural Skills. We utilize a five point Likert scale from strongly disagree (1) to strongly agree (5) to collect and analyses data.A total of 44 questionnaires were distributed to hospital senior managers; 40 questionnaires were returned. Validity of questionnaire was approved under the guidance of the research supervisor and consultants and the reliability was obtained via cronbach Alpha $(\alpha=.863)$ that indicate high reliability.

\subsection{Statistical analysis}

The data was analyzed using Spss 16. Descriptive statistical analysis included mean and standard deviation. For Inferential statistical analysis we used independent t-test (P.value<.05). Based on the responses obtained from each manager, score of each component was calculated. Finally by adding the score of three components, level of cultural competence was determined. If the final score of cultural competence was between 30-60, managers were classified at cultural incapacity level; if it was between 61-90, they were classified at cultural blindness level; if it was between 91-120, they were classified at cultural pre-competence level, and if final score for manager cultural competence was between 121-150, they were classified at culturally competent level.

\subsection{Ethical issues:}

Ethical issues (including plagiarism, informed consent, misconduct, data fabrication and/or falsification, double publication and/or submission, redundancy, etc.) have been completely observed by the authors. By the way, our study was approved by the ethics committee of Isfahan University of Medical Sciences (MUI).

\section{RESULTS}

The results of this research, studying cultural competence in male and managers of training hospitals in Isfahan, are shown in table 1 and 2.

$40(90.9 \%)$ of the 44 senior managers completed the questionnaires, 21(52.5\%) were male and 19(47.5\%) female. The age range of managers was from 30 to 60 years. $37.5 \%$ of participant having B.S. degree, $17.5 \%$ having M.S. degree, and $45 \%$ were physician. The details of demographic characteristics of the respondents are presented in Table 1.

Table 2 showed the mean score of cultural competence components for male and female senior managers in training hospitals. In this table, there are a little different between score of cultural competence component of male and female. Mean score of cultural competence for male in hospitals is 133.36 and for female is 133.24.Thus senior managers' cultural competence is high in hospitals.

To sharpen the conclusion independent t-test was performed and results showed that there was no significant difference for senior manager's level of cultural awareness, knowledge, skills, and cultural competence for male and female. So that male and female senior manager's cultural awareness, knowledge, and skills in hospitals are same and senior managers cultural competence in hospitals is same, thus they classified as cultural competence level. 


\section{TABLES}

Table 1. Socio-demographic characteristics of participants

\begin{tabular}{|c|c|c|}
\hline Variable & \multicolumn{2}{|l|}{ Number (\%) } \\
\hline \multirow[t]{2}{*}{ Gender } & male & $21(52.5)$ \\
\hline & female & 19(47.5) \\
\hline \multirow[t]{3}{*}{ Age } & $31-40$ & $7(17.5)$ \\
\hline & $41-50$ & $29(72.5)$ \\
\hline & $51-60$ & $4(10)$ \\
\hline \multirow[t]{3}{*}{ Work experience } & $5-10$ & $3(7.5)$ \\
\hline & $11-20$ & $19(47.5)$ \\
\hline & $21-30$ & $18(45)$ \\
\hline \multirow[t]{3}{*}{ Education } & B.S degree & $15(37.5)$ \\
\hline & M.S degree & $7(17.5)$ \\
\hline & Physician & $18(45)$ \\
\hline
\end{tabular}

Table 2. Mean score and analysis of Independent T-Test for senior manager's cultural competence

\begin{tabular}{|l|l|l|l|l|}
\hline Variable & Gender & N & Mean Score & \multirow{2}{*}{ Sig } \\
\hline \multirow{2}{*}{ Cultural awareness } & Male & 21 & 44.21 & \multirow{2}{*}{$.415^{*}$} \\
\cline { 2 - 4 } & female & 19 & 43.62 & \\
\hline \multirow{2}{*}{ Cultural knowledge } & Male & 21 & 45.15 & \multirow{2}{*}{.978} \\
\cline { 2 - 4 } & Female & 19 & 45.12 & \\
\hline \multirow{2}{*}{ Cultural skills } & Male & 21 & 44 & \multirow{2}{*}{424} \\
\cline { 2 - 4 } & Female & 19 & 44.5 & \\
\hline
\end{tabular}




\begin{tabular}{|l|l|l|l|l|}
\hline Cultural competence & Male & 21 & 133.36 & \multirow{2}{*}{.960} \\
\cline { 2 - 4 } & Female & 19 & 133.24 & \\
\hline
\end{tabular}

* Significant at the .05 level

\section{DISCUSSION AND CONCLUSION}

\subsection{DISCUSSION}

Cultural competence refers to a set of congruent attitudes, practices, policies, and structures that come together in a system or agency and enable professionals to work more effectively in cross-cultural situation $[18,23]$. In this study to determine the level of cultural competence, score of each cultural competence component such as cultural awareness, cultural knowledge, and cultural skill calculated and final score of cultural competence was determined. These components were also used by other researchers in preparation of a models and making tools for assessing cultural competence.

Tilki and O'Shaughnessy (2007) in their study provided a cultural competence training model for physiotherapy to improve care and increase job satisfaction [24]. The Core components in their model were cultural awareness, cultural knowledge, and cultural sensitivity which are similar to cultural competence component in our study [24]. Leung and Cheung (2013) in their research, approving validity and reliability of cultural competence self-assessment tool for children's protective services and classified main components in this assessing tool in three groups, including cultural attitude, cultural knowledge, and cultural skills [25]. Also they introduce this tool as an educational means for all professional in diverse organization for effective communication and interaction which are similar to core component in our study for effective communication [25]. Durand et al (2012)in their study, aiming to improve the student's level of cultural competence, with assessing pharmacy's student cultural competence at the begin and end of the course with using the inventory for assessing the process of cultural competence-student version (IAPCC-SV), that is based on bacote's model in cultural competence, measured cultural awareness, knowledge, skills, encounter, and desire in which cultural awareness, cultural knowledge and cultural skills are similar to core component in our study[26]. Dusi et al (2014) introduced social skills, attitude, and cultural knowledge as main component for effective intercultural communication in multi cultural situations which these components are also similar to cultural competence component in our study [27]. Acosta et al (2011) in their study classified core component of cultural competence in four groups, including cultural awareness, cultural knowledge, cultural skills, and cultural advocacy [28]. They explained that these components have been developed to help guide their medical school curriculum and encourage the faculty to facilitate and integrate these core components of cultural competence in their course curricula, which are similar to cultural competence component in our study [28].

In all of these studies as our study, found cultural awareness, cultural knowledge, and cultural skills as core cultural competence component.These components are critical elements for achieving high level of cultural competence and effective interpersonal communication and interaction. These components were used to evaluate level of cultural competence.

\subsection{Conclusion}

Effective communication and interaction between managers and staff is a prerequisite for organization success. Cultural competence is known as a strategy for effective communication and a key factor in management for any organization. Based on our study and other researches Cultural awareness, cultural knowledge and cultural skills are critical element for effective interaction and communication between people and should be used for evaluating and achieving high level of cultural competence

\section{ACKNOWLEDGEMENTS}

This article is resulted from an M.SC. Thesis in 2015 at Isfahan Medical University (MUI), IRAN. We would like to acknowledge all respondents.

\section{REFERENCES}

[1] Mosadeghrad, AM, A study of Relationship between Leadership Style Managers and Hospital Efficiency in Isfahan University Hospitals, Faculty of Admin Sciences \& Econ University of Isfahan, 17(4). 2006.

[2] Dargahi, H. Shaham, G, Self-assessment of Administrators' Managerial Skills and their Relationship with Effective Management in Hospitals of Tehran University of Medical Sciences, International Journal of Hospital Research, 1(1). 2012, 65-70. 
[3] Sajadi, HS. Hadi, M. Maleki, M. Tourani, S, Does Transfer of Hospital Governance to Board of Trustees per se Lead to Improved Hospital Performance?, International Journal of Hospital Research,1(2). 2012, 97-102.

[4] Spaho, K, Organizatinoal Communication as an Important Factor of Company Success: Case Study of Bosnia and Herzegovin, Business Intelligence Journal, 4(2). 2011, 390-4.

[5] Barzegar, M. Afzal, E. Tabibi, SJ. Delgoshaei, B, Relationship between Leadership Behavior, Quality of Work Life and Human Resources Productivity: Data from Iran, International Journal of Hospital Research, 1(1). 2012.

[6] Osula, B. Irvin, S, Cultural Awareness in Intercultural Mentoring: A Model for Enhancing Mentoring Relationships, International Journal of Leadership Studies, 5(1). 2009, 37-50.

[7] s. Asef zade, a. Rezapour, Helth management. (Qazvin: Qazvin University of medical publisher, 2006.)

[8] Kebriaei, A. Rakhshaninejad, M. Afshari, Z. Mohseni, M, Psychological Empowerment in Hospital Administrative Staff Predicts their Organizational Commitment, International Journal of Hospital Research, 2(4). 2013, 171-6.

[9] Gabriel RL, organizational communication bridging the gap between managers and employees, School of Professional Studies, Gonzaga University.

[10] Ruck, K. Welch, M, Valuing internal communication; management and employee perspectives, Public Relations Review, 38(2). 2012, 294-302.

[11] Wilson, A, From the Perspective of CEOs: What Motivates Hospitals to Embrace Cultural Competence? ,Health Care Management,55(5). 2010, 339-52.

[12] Mitrofan, N. Bulborea, A, The Role of Organizational Communication in Structuring Interpersonal Relationships, Procedia-Social and Behavioral Sciences, 76. 2013, 511-5.

[13] Aghamolaei, T. Tavafian, SS. Hasani, L. Moeini, B, Nurses' Perception of Nurse-physician Communication: A Questionnaire-based Study in Iran, International Journal of Hospital Research, 1(2).2012.

[14] Van Ngo, H. Cultural Competence, Prepared for Citizenship and Immigration Canada, 2008.

[15] [15] Lolli, JC. Interpersonal communication skills and the young hospitality leader: Are they prepared? , International Journal of Hospitality Management, 32. 2013, 295-8.

[16] Quist, RM. Law, AV, Cultural competency: agenda for cultural competency using literature and evidence, Research in Social and Administrative Pharmacy, 2(3). 2006, 420-38.

[17] Betancourt, JR. Green, AR. Carrillo, JE. Park, ER, Cultural competence and health care disparities: key perspectives and trends, Health affairs, 24(2). 2005, 499-505.

[18] Cross, TL. Benjamin, MP. Isaacs, MR, towards a culturally competent system of care: CASSP Technical Assistance Center, Georgetown University Child Development Center, 1998.

[19] Campinha-Bacote, J. The process of cultural competence in the delivery of healthcare services: A model of care, Journal of Transcultural Nursing, 13(3). 2002, 181-4.

[20] Gibson, D. Zhong, M, Intercultural communication competence in the healthcare context, International Journal of Intercultural Relations, 29(5). 2005, 621-34.

[21] Welch, M. Appropriateness and acceptability: Employee perspectives of internal communication, Public Relations Review, 38(2). 2012, 246-54.

[22] Reid, P. A Brief Note on the Importance of Cross-Cultural Competence to Leadership, 2011.

[23] Olavarria, M. Beaulac, J. Belanger, A. Young, M. Aubry, T. Standards of Organizational Cultural Competence for Community Health and Social Service Organizations, University of Ottawa: Centre for Research on Community Services, 2005.

[24] O'Shaughnessy, DF. Tilki, M. Cultural competency in physiotherapy: a model for training, Physiotherapy, 93(1). 2007, 69-77.

[25] Leung, P. Cheung, M. Factor analyzing the "ASK" cultural competency self-assessment scale for child protective services, Children and Youth Services Review, 35(15). 2013, 1993-2002.

[26] Durand, C. Abel, C. Silva, M. An elective course in cultural competence, Currents in Pharmacy Teaching and Learning, 6(12).102-8.

[27] Dusi, P. Messetti, G.Steinbach, M. Skills, Attitudes, Relational Abilities \& Reflexivity: Competences for a Multicultural Society, Procedia-Social and Behavioral Sciences, 112. 2014, 538-47.

[28] Acosta, D. Tsegai, A. Gardner, V. Racansky, P. Core Guiding Principles for Cultural Competence for Medical Education. 